\title{
Empirical Mode and Enlightenment on Urban Public Crisis Management of Developed Countries
}

\author{
Yongchang Ren \\ College of Information Science and Technology, Bohai University, Jinzhou, 121013, China \\ 1213552916@qq.com
}

\begin{abstract}
Keywords: developed countries; urban management; public crisis; management mechanism; experience enlightenment
\end{abstract}

\begin{abstract}
Increasingly frequent urban public crisis put forward new challenges for governments work. By analyzing the public city crisis management of USA, Japan, EU, Russia and other developed countries obtain the experience enlightenment of dealing with urban public crisis. These include: speeding up the development of national emergency law, establish and improve the safety laws and regulations, the establishment of special coordinating institution for the government and social organizations, culture the safety awareness and crisis culture for citizens, build effective crisis information management system, establish a scientific crisis performance assessment system. Results of this study make up the deficiencies of Chinese urban public crisis management, and serve for improving the level of urban crisis management and promoting the urban sustainable development.
\end{abstract}

\section{Introduction}

The city as a product of social productive forces, with the growing of size and the increasing of resident population, has become an important carrier of the interaction between the production relations and the interdependence of the different stakeholders. The emergence of the city, is not only an important symbol of the progress of human civilization, but also the development of productive forces, improve the living environment and improve the relations of production to enrich an important force. Cities bring people a better life, but also brought a more serious public crisis. Increasingly frequent urban public crisis put forward new challenges for governments work, the ability to effectively carry out the work of urban public crisis management has become an important measure of overall national strength. Research scholars from various countries will have to shift the focus from the political crisis to a public crisis in the past, and has made a series of important research results, provides a powerful theoretical support for national urban public crisis management [1,2]. Although the world's cultures and different national conditions, but in most countries, especially the developed countries on a common crisis management follow the "unified management, clear division of labor laws and improve the information flow, the people involved," the guiding ideology. Public crisis management mechanism have their own distinctive some developed countries have established to improve the sound management of public crisis has a certain significance.

\section{Experience on Urban Public Crisis Management of Developed Countries}

Public city crisis is a common problem faced by the world. After years of crisis disposal, Western developed countries based on their actual conditions formed a more perfect their own distinctive urban public crisis management mechanism. By analyzing the public city crisis management of USA, Japan, EU, Russia and other developed countries obtain the enlightenment of dealing with urban public crisis [3-5].

(1) United States

US government takes proactive measures to reduce the risk of a crisis, also uses emergency to reduce the loss caused by risk as possible. The United States has established a relatively sound 
public crisis management system, with the operational aspects of the standardization and institutionalization, flexible organizational structure and extensive emergency support measures complete and other features. American public crisis management system through legalization means the efficient core coordinating body, a complete crisis response plan, mature social response capacity and comprehensive crisis response network inclusion in the system, and achieved very good results. US public crisis management has the following two characteristics:

The first is a complete risk assessment system. Risk assessment system has been formed in the United States, including risk identifying, risk assessing, risk planning, and execution and control risks. This risk assessment system is gradually explored during the crisis out; in line with practice requirements for the safe and orderly operation of the State provide a favorable environment protection. Has four characteristics: First, orderly, can effectively mitigation planning, risk assessment and contingency plans to combine; the second is integrated and coordinated, the United States established the committee for disaster reduction, and set the corresponding planning group to strengthen the various regions and departments coordination; and third is to use high-tech means, using state of the crisis the whole process of risk assessment; Fourth, open and transparent, to establish a platform for the orderly society participation in risk assessment.

The second is the comprehensive crisis response plan. Through the development of a comprehensive contingency plan for crisis management in the overall deployment, before the crisis on the development of a detailed response plans, both federal contingency plan in general, there are specific operational outline for the special nature of the crisis event. Federal emergency plan is one of the public crisis management Basic Law, signed by the federal government departments and agencies, the Government legally binding document, specifically into basic programs and a range of accessories designed to assist state and local governments to deal with any major natural disasters, man-made disasters and emergencies.

The third is the full social participation. The public can participate in the community, non-profit organization management, formed a comprehensive social participation mechanisms for governments, organizations, combining the public and improve the government's ability to respond to crises, to ease the side effects of the crisis in public, and strengthen public awareness of government trust. When the crisis comes, timely treatment and rescue government, NGOs and the public to participate in public crisis management and rescue systems, including the independent aid organizations of civil society, civil community disaster defense system, non-governmental charitable organizations, religious groups and civil society, effectively assist local government's handling of the crisis event.

(2) Japanese

Japanese government crisis management is gradually improving with frequent crises, established a central and local crisis management system. Legal, institutional, function-based, as the supreme commander of the prime minister, responsible for the overall coordination of the Cabinet Committee liaison to develop crisis response by the Security Council of the Central Disaster Prevention Conference, the financial crisis and other decision-making bodies Strategies conference, the National Land Agency, the Meteorological Agency The agency and the Fire department and other departments with the implementation of the specific circumstances. Meanwhile, Japan also attaches great importance to the process of citizen participation in crisis, non-profit organizations, businesses and other forces, national education through a variety of channels, community organizations, and the establishment of the linkage relationship with society, to ensure the realization crisis pluralistic participation. Public crisis management in Japan has the following two characteristics:

First, set up a unified organization. The Japanese government established crisis management system a cabinet minister as the supreme commander of the crisis management, responsible for the national crisis management. Unified organization consists of three main components: a coordinator, director of crisis management, crisis management, assist the chief executive, the coordination of various departments; technical and command sector comprehensive disaster prevention department, crisis management, information management and action by the instruction department components. 
The former is responsible for the collection of information, analysis and strategic judgment, which is responsible for direct and coordinate the event of a disaster; the highest executive decision-making department, the chief executive of disaster prevention meetings, crisis management, the direct leadership, to develop or modify regional disaster planning and supervision of program implementation .

(3) European Union

EU public crisis management mechanism to deal with the BSE crisis in the process of gradually develop. With the formal operation of the relevant laws and regulations and constantly we enrich the European Food Safety Authority, the European Union in order to safeguard public health primary purpose of crisis management mechanism perfected. When the first BSE scare peaked, the EU immediately took a series of strong measures, and gradually forms a centralized management mechanism to deal with the outbreak of the BSE crisis. The European Commission is a mechanism in which the governing body, the Scientific Steering Committee and the specialized scientific committee under consultation in decision-making, crisis early warning, risk assessment, inspection and supervision functions. In the process of disposal BSE, the existing crisis management mechanism achieves a major change. EU public crisis management has the following three features:

The first is centralized emergency management system. In the case of the Member State concerned cannot effectively control the danger, the commission has the right to prohibit the export, transportation, marketing and other necessary interim measures. Such as the danger has not been effectively controlled, the commission set up by the Food Safety Authority representatives to participate in the crisis management team, and the representatives of Member States, with the European commission on behalf of the chairman of the Standing Committee of the assistance, to take more effective measures.

Second, improve the legal system. EU based on "EU Treaty" in the provisions relating to public health and consumer protection, the use of secondary legislative power have passed on food safety, animal feed, particularly dangerous substances, animal quarantine, genetically modified food, environmental protection, trade and other restrictions and a ban series of consumer protection laws and regulations. On the other hand, the Council of Europe not only for the development of a unified food law opens the way, but also for the institutional arrangements of the EU crisis management and authority of the Commission to make a more clearly defined.

(4) Russia

Russian public crisis management system is more complete and unified, department of crisis management are more and involved in the fields of relatively broad. Permanent establishment of public crisis management is the Russian Federation Security Council, chaired by the federal president, federal secretary of the meeting appointed by the president directly responsible to the President. When the crisis nowadays, the Russian Federation Security Council to use the "emergency decision-making mechanisms." When faced with specific crises, in addition to a permanent crisis management mechanism, it has also set up a temporary agency dedicated to the handling of crises. Russian Federal Assembly Standing Committee, including the President, Prime Minister, Secretary of the Conference, the Federal Security Secretary, defense minister and foreign minister, as a member of other heads of departments involved in crisis management. Russian public crisis management has the following three features:

The first is strong systems supported crisis management. The main responsibilities of crisis management support systems, is that when a crisis occurs, the effective implementation of the central command system crisis made the decision to ensure the active cooperation of all sectors of social decision-making effectively enforced. As a direct crisis management mechanism, the Russian crisis management support systems, including national security, fire, and police, healthy, medical care, social security and transport sectors.

Second, give full play to the role of modern media. Russian government attaches great importance to control and regulate the media, using various means to establish communication channels between the media and ensure greater transparency, openness crisis management work. Head of the President of the Russian Federation and other relevant departments are often televised 
speech, held a press conference or an interview with reporters in the mainstream media, publish or disclose timely crisis-related information, which will enhance national confidence, eliminate public tension and fear.

\section{Enlightenment on Urban Public Crisis Management of Developed Countries}

Through in-depth study of the national urban America, Japan, European Union, Russia and other public crisis management, a clear understanding of the gap with the international advanced level in this field. International advanced management experience and successful operation of the mechanism for the management of urban public crisis pointed out the direction, but also for specific conduct crisis management provides methods and technology, it is our crisis managers and academic researchers to learn from [6].

(1) Speeding up the development of national emergency law. When people's lives and property are seriously threatened or lost, social and political stability and order was a major influence, and even national sovereignty is threatened other major crisis occurs, it should be a state of emergency, which is taken by the State Compulsory measures. Emergency help to quickly and effectively integrate social forces, improve the efficiency of crisis response. But the state of emergency in certain extent, limit the personal freedom of citizens, must be emergency legislation from the law, to regulate. But at this stage, China has some of the more fragmented local laws or regulations, but applies nationwide law does not specifically crisis. No state of emergency law, we cannot meet the comprehensive requirements of crisis management. Therefore, we must accelerate the development of the state of emergency law.

(2) Establish and improve the safety laws and regulations. Improve the legal system for the government to conduct crisis management provides a legal and institutional norms, crisis management measures to ensure the rapid and effective implementation, to protect people's lives and property. At the same time, to protect the exercise of emergency powers of the government and departments to properly regulate the process of crisis management, the reduction of civil rights violations. Improve the legal system also allows the government that the laws in the administrative process, the administration, reducing the crisis due to the problems caused by the government itself. The specific measures to tackle the crisis countries in the form of laws and regulations promulgated and implemented, can make crisis management more standardized and quickly.

(3) The establishment of special coordinating institution for the government and social organizations. Developed countries in order to coordinate government and social organizations in matters of public crisis management, within the government set up a special coordinating body to ensure the smooth flow channels of cooperation. China should set up a special coordinating body, by the relevant government departments and social organizations staff, is responsible for the unified command and decentralized society organizations and other social forces, the government's ability to strengthen cooperation with social organizations, in order to guarantee formal organizational channels of cooperation have order to carry out. Special coordinating body to guide the implementation of special programs in the normal, and strengthen the links between government and social organizations; can also coordinate cooperation issues between the government and social organizations in the public crisis management, streamline cooperation and provide a formal channel for promoting cooperation organization .

(4) Culture the safety awareness and crisis culture for citizens. National awareness of the strength of the public security is directly related to the effect of crisis management in the public sector, for a country, the idea of public safety of citizens is a valuable spiritual wealth, but also the foundation of the national public crisis management. Developed countries not only focus on strengthening public awareness of the crisis management of public managers, but also for the general public to educate and train regular sense of crisis. Local governments and various school has a crisis management courses, propaganda disaster prevention knowledge, the country with disaster prevention center for people to disaster prevention education through a variety of facilities for people to experience the earthquake, tsunami, typhoons and other natural disasters, harm comes can reduce losses caused by disasters. 
(5) Establish a scientific crisis performance assessment system. Integration of existing information management system, establish and improve the reporting system of public crisis, the first time publish information on the crisis. Further optimize the crisis management system to improve the efficiency of crisis management by building a sound communication mechanism. Core information management system is a network media. Internet media has an open, fast, interactive and other notable features, online sources of information is extremely difficult to control, information filtering very difficult. Therefore, to improve crisis communication mechanisms, must pay attention to online media, pay attention to the online public opinion to deal with, guidelines for network crisis information and communication order.

(6) Establish a scientific performance evaluation system crisis. Risk assessment is the process of public service or set and achieves program objectives, and achieves the results of the assessment system. By risk assessment, to obtain the purpose that estimate and evaluate the results of handling crisis management and its impact, finally draw conclusions to the results of crisis management. First, determine a reasonable risk assessment indicators, the crisis prevention, crisis management plans, crisis management process flow, crisis management, etc. into the results of the index system; and then to evaluate the micro and macro levels, in the event of a crisis assessment and feedback process, to crisis management in public institutions and their affiliated expert system as the main crisis information system to monitor the use of the results of the key indicators to be.

\section{Conclusion}

Public city crisis management generally include early warning before the crisis happened, emergency treatment when occurred, recovery and reconstruction after the occurrence, a variety of people and the protection of property and so on, is a huge project. Since the theory of Chinese urban public crisis management started late, many important issues have not been effectively resolved; in theory and in practice caused some degree of confusion. Through in-depth study of typical national and international crisis management experience in large cities, obtained the inspiration for Chinese urban public crisis management, make up the deficiencies of Chinese urban public crisis management experience, and serve for improving the level of urban crisis management and promoting the urban sustainable development.

\section{Acknowledgment}

This work is supported by social science fund project of Liaoning province (L12BZZ009): Research on management mechanism for urban public crisis.

\section{References}

[1] X. M. Zhang, "Public sector crisis management," Renmin University of China press, 2006.

[2] Tomáš Ludík and Jaroslav Ráček, "Process Methodology for Emergency Management," IFIP Advances in Information and Communication Technology, vol. 35, no. 9, pp. 302-309, 2011.

[3] Z. C. Jiang, "Research on Emergency Decision - making Theory and Coping Mechanism of Public Crisis Management in Urban Agglomeration," Doctor's Shanghai University, 2014.

[4] X. P. Zhang, "A Study on System Construction and Capability Evaluation of Public Crisis Management," Doctor's degree of Dalian University of Technology, 2011.

[5] S. R. Chen, "Research on Communication of Public Crisis Management," Doctor's degree of East China Normal University, 2009.

[6] Hye-Young Lee, Mi-Na Oh, Yong-Shik Park, Chaeshin Chu, Tae-Jong Son, "Public Health Crisis Preparedness and Response in Korea," Osong Public Health and Research Perspectives, vol. 4, no. 5, pp. 278-284, 2013. 